\title{
MIXED CONVECTION IN THE STAGNATION-POINT FLOW OVER A VERTICAL STRETCHING SHEET IN THE PRESENCE OF THERMAL RADIATION
}

\author{
S. MANJUNATHA* \\ Department of Engineering Mathematics \\ Christ University Faculty of Engineering \\ Kanminike, Kumbalgodu, Mysore Road \\ Bengaluru-560074 Karnataka-State, INDIA \\ E-mail: manjubhushana@gmail.com \\ B.J. GIREESHA and C.S. BAGEWADI \\ Department of Studies and Research in Mathematics \\ Kuvempu University \\ Shankaraghatta-577 451, Shimoga, Karnataka, INDIA
}

\begin{abstract}
An unsteady two-dimensional stagnation-point mixed convection flow of a viscous, incompressible dusty fluid towards a vertical stretching sheet has been examined. The stretching velocity and the free stream velocity are assumed to vary linearly with the distance from the stagnation point. The problem is analyzed using similarity solutions. The similarity ordinary differential equations were then solved numerical by using the RKF-45 method. The effects of various physical parameters on the velocity profile and skin-friction coefficient are also discussed in this paper. Some important findings reported in this work reveal that the effect of radiation has a significant impact on controlling the rate of heat transfer in the boundary layer region.
\end{abstract}

Key words: boundary layer flow; stretching porous surface; mixed convective parameter; thermal radiation; numerical solution; dusty fluid; free stream velocity.

AMS Subject Classification (2000): 76T15, 80A20;

\section{Introduction}

The flow in the neighborhood of a stagnation line has attracted many investigators during the past several decades because of its wide industrial and technical applications such as cooling of electronic devices by fans, cooling of nuclear reactors during emergency shutdown, heat exchangers placed in a low-velocity environment, solar central receivers exposed to wind currents, and many hydrodynamic processes. Hiemenz (1911) was the first to study the two-dimensional stagnation-point flow and obtained an exact similar solution of the governing Navier-Stokes equations. Since then many investigators have considered various aspects of such a flow and obtained similarity solutions. In pure forced convection the stagnation point flow results from a two-dimensional flow impinging on a surface at right angle and flowing thereafter symmetrically about the stagnation line. In mixed convection the flow and thermal fields are no longer symmetric with respect to the stagnation line. In addition, the local heat transfer rate and the local shear stress can be significantly enhanced or diminished in comparison to the pure forced convection flow. The combined forced and free convection (mixed convection) flow is important when the buoyancy forces due to the temperature difference between the surface and the free stream become large, which in turn significantly affect the flow and the thermal fields. Ramachandran et al. (1988) studied laminar mixed convection in two-dimensional stagnation flows around

\footnotetext{
* To whom correspondence should be addressed
} 
heated surfaces by considering both cases of an arbitrary wall temperature and arbitrary surface heat flux variations. They found that a reverse flow develops in the buoyancy opposing flow region, and dual solutions are found to exist for a certain range of the buoyancy parameter. This work was then extended by Devi et al. (1991) for an unsteady case and by Lok et al. $(2005$; 2006) for a vertical surface immersed in a micro polar fluid. Takhar et al. (2005) studied unsteady mixed convection flow of a viscous incompressible, electrically conducting fluid in the vicinity of a stagnation-point adjacent to a heated vertical surface. Both the constant wall temperature and constant heat flux conditions were considered.

All of the works mentioned above considered the flow along normal to a vertical or horizontal surface at rest in fluid phase only. The stagnation-point flows towards a surface which is moved or stretched have been considered by Chiam (1996), Mahapatra and Gupta (2001), and Nazar et al. (2004). This interest stems from the fact that mixed convection due to moving surfaces has wide applications in material processing systems such as welding, extrusion of plastics, hot rolling, paper drying etc. Recently, Ishak et al. (2006; 2006) discussed the mixed convection boundary layers in the stagnation-point flow toward a stretching vertical sheet. Vajravelu and Nayfeh (1992) discussed hydromagnetic flow of a dusty fluid over a stretching sheet. Gireesha et al. $(2011 ; 2011)$ studied unsteady hydromagnetic boundary layer flow and heat transfer of a dusty fluid over a stretching sheet for both steady and unsteady flow. Further they studied (Gireesha et al., 2011) boundary layer flow and heat transfer of a dusty fluid over a stretching vertical surface. Motivated by the work of Vajravelu and Nayfeh (1992) and Ishak et al. $(2006 ; 2006)$ we study the unsteady mixed convection boundary layer flow of a viscous, incompressible, dusty fluid near the stagnation point on a vertical surface. The partial differential equations governing the flow and temperature fields are reduced to ordinary differential equations. The resulting systems of ordinary differential equations are solved numerically using the RKF-45 method with the help of symbolic algebra software Maple. Further, both the variable wall temperature (VWT) and variable heat flux (VHF) conditions have been considered.

\section{Mathematical formulation of the problem}

Consider the two-dimensional unsteady boundary layer flow of a viscous and incompressible dusty fluid (with electric conductivity $\sigma$ ) in a stagnation point over a vertical stretching sheet in the presence of time dependent free stream. The fluid occupies the upper half plane i.e., $y>0$. The flow is considered to be generated by stretching of an elastic boundary sheet from a slit with the application of two equal and opposite forces in such a way that the velocity of the boundary sheet is linear and directed along the coordinate $x$. A uniform magnetic field $B_{0}$ is imposed along the $y$-axis.

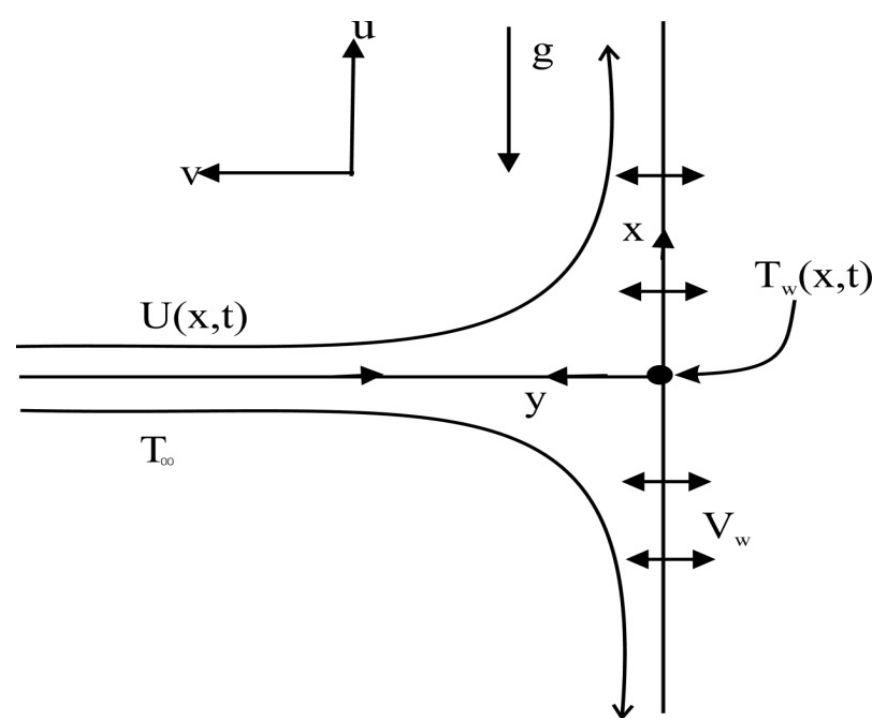

Figure: Schematic diagram of the flow geometry. 
Two-dimensional boundary layer equations of a dusty fluid in usual notation are Vajravelu and Nayfeh (1992)

$$
\begin{aligned}
& \frac{\partial u}{\partial x}+\frac{\partial v}{\partial y}=0 \\
& \frac{\partial u}{\partial t}+u \frac{\partial u}{\partial x}+v \frac{\partial v}{\partial y}=-\frac{\partial p}{\partial x}+v \frac{\partial^{2} u}{\partial y^{2}}+\frac{k N}{\rho}\left(u_{p}-u\right)+g \beta^{*}\left(T-T_{\infty}\right)-\frac{\sigma B_{0}^{2}}{\rho} u \\
& \frac{\partial u_{p}}{\partial t}+\frac{u_{p} \partial u_{p}}{\partial x}+\frac{v_{p} \partial u_{p}}{\partial y}=\frac{k}{m}\left(u-u_{p}\right), \\
& \frac{\partial v_{p}}{\partial t}+\frac{u_{p} \partial v_{p}}{\partial x}+\frac{v_{p} \partial v_{p}}{\partial y}=\frac{k}{m}\left(v-v_{p}\right), \\
& \frac{\partial\left(\rho_{p} u_{p}\right)}{\partial x}+\frac{\partial\left(\rho_{p} v_{p}\right)}{\partial y}=0 .
\end{aligned}
$$

We have the following nomenclature:

$(u, v)$ and $\left(u_{p}, v_{p}\right)$ denote the velocity components of the fluid and particle phase along the $x$-and $y$-axis, respectively. Further $\mu, \rho, B_{0}, \rho_{p}, K, N, m g$ and $\beta^{*}$ are the coefficients of viscosity of the fluid, density of the fluid, induced magnetic field, density of particle phase, Stokes constant, number density, mass of dust particle, acceleration due to gravity and volumetric coefficient of thermal expansion, respectively. In deriving these equations, the Stokesian drag force is considered for the interaction between the fluid and particle phase and the induced magnetic field is neglected. It is also assumed that the external electric field is zero and the electric field due to polarization of charges is negligible.

Here, in free stream $u=U(x, t)=\frac{b x}{1-\alpha t}$ is defined as

$$
U \frac{\partial U}{\partial x}+\frac{\partial U}{\partial t}=-\frac{1}{\rho} \frac{\partial p}{\partial x}-\frac{\sigma B_{0}^{2}}{\rho} U
$$

The boundary conditions applicable to the above problem are

$$
\begin{aligned}
& u=U_{w}(x, t), \quad v=V_{w}(x, t) \quad \text { at } \quad y=0, \\
& u \rightarrow 0, \quad u_{p} \rightarrow 0, \quad v_{p} \rightarrow v, \quad N \rightarrow k \rho \quad \text { as } \quad y \rightarrow \infty
\end{aligned}
$$

where $U_{w}=\frac{c x}{1-\alpha t}$ is the velocity of the sheet $U(x, t)=\frac{b x}{1-\alpha t}$ free stream velocity of the fluid, $V_{w}(x, t)=-\frac{v_{0}}{\sqrt{(1-\alpha t)}}$ is the suction velocity and $c$ is the initial stretching rate being a positive constant, 
$k$ is constant density ratio, $\alpha$ is a positive constant which measures the unsteadiness. Equations (2.1) to (2.5) subjected to boundary conditions (2.7), admit self-similar solution in terms of the similarity function $f$ and the similarity variable $\eta$ and are defined by

$$
\begin{array}{ll}
u=\frac{c x}{1-a t} f^{\prime}(\eta), \quad v=-\sqrt{\frac{c v}{(1-a t)}} f(\eta), \quad \eta=\sqrt{\frac{c}{v(1-a t)}} y, \\
u_{p}=\frac{c x}{1-a t} F(\eta), \quad v_{p}=\sqrt{\frac{c v}{(1-a t)}} G(\eta), \quad \rho_{r}=H(\eta), \quad B_{0}^{\prime}=B_{0}(1-\alpha t)^{-\frac{1}{2}}
\end{array}
$$

where a prime denotes the differentiation with respect to $\eta$. Substituting Eq.(2.6) and the set of Eqs (2.8) into Eqs (2.1) to (2.5) gives

$$
\begin{aligned}
& f^{\prime \prime \prime}(\eta)+f(\eta) f^{\prime \prime}(\eta)-f^{\prime}(\eta)^{2}-A\left[f^{\prime}(\eta)+\frac{\eta}{2} f^{\prime \prime}(\eta)\right]+ \\
& +l \beta H(\eta)\left[F(\eta)-f^{\prime}(\eta)\right]-M\left(f^{\prime}(\eta)-\lambda\right)+A \lambda+\lambda^{2}+\lambda^{*} \theta(\eta)=0, \\
& A\left[F(\eta)+\frac{\eta}{2} F^{\prime}(\eta)\right]+G(\eta) F^{\prime}(\eta)+F(\eta)^{2}-\beta\left[f^{\prime}(\eta)-F(\eta)\right]=0, \\
& \frac{A}{2}\left[G(\eta)+\eta G^{\prime}(\eta)\right]+G(\eta) G^{\prime}(\eta)+\beta[f(\eta+G(\eta)]=0, \\
& F(\eta) H(\eta)+G^{\prime}(\eta) H(\eta)+H^{\prime}(\eta) G(\eta)=0,
\end{aligned}
$$

where $\rho_{r}=\frac{\rho_{p}}{\rho}$ is the relative density, $A=\frac{\alpha}{c}$ is the parameter that measures the unsteadiness, $l=\frac{m N}{\rho_{p}}$ is the mass concentration, $M=\frac{\sigma B_{0}^{2}}{\rho b}$ is the magnetic field parameter, $\lambda=\frac{b}{c}$ is the ratio of the free stream velocity parameter to the stretching velocity parameter, $\lambda^{*}=\frac{\mathrm{Gr}_{x}}{\mathrm{Re}_{x}^{2}}$ is the mixed convective parameter, $\mathrm{Gr}_{x}=\frac{g \beta^{*}\left(T_{w}-T_{\infty}\right) x^{2}}{v^{2}}$ is the local Grashof number, $\operatorname{Re}_{x}=\frac{u_{w} x}{v}$ is the local Reynolds number and $\beta=\frac{1}{\tau b}(1-a t)$ is the fluid-particle interaction parameter.

The corresponding boundary conditions are transformed to

$$
\begin{array}{ll}
f^{\prime}(\eta)=1, & f(\eta)=R \quad \text { at } \quad \eta=0, \\
f^{\prime}(\eta)=\lambda, \quad F(\eta)=\lambda, \quad G(\eta)=-f(\eta), \quad H(\eta)=E \quad \text { as } \quad \eta \rightarrow \infty
\end{array}
$$

where $R=\frac{v_{0}}{\sqrt{v c}}$ is the suction parameter and $E$ is the density ratio. 


\section{Heat transfer analysis}

The boundary layer heat transport equations in the presence of thermal radiation in space for two dimensional flows are given by Schlichting (1968)

$$
\begin{aligned}
& \rho c_{p}\left[\frac{\partial T}{\partial t}+u \frac{\partial T}{\partial x}+v \frac{\partial T}{\partial y}\right]=k^{*} \frac{\partial^{2} T}{\partial y^{2}}+\frac{N c_{p}}{\tau_{T}}\left(T_{p}-T\right)+\frac{N}{\tau_{v}}\left(u_{p}-u\right)^{2}-\frac{\partial q_{r}}{\partial y}, \\
& N c_{m}\left[\frac{\partial T_{p}}{\partial t}+u_{p} \frac{\partial T_{p}}{\partial x}+v_{p} \frac{\partial T_{p}}{\partial y}\right]=-\frac{N c_{p}}{\tau_{T}}\left(T_{p}-T\right)
\end{aligned}
$$

where $T$ and $T_{p}$ are the temperature of the fluid and dust particle, $c_{p}$ and $c_{m}$ are the specific heat of the fluid and dust particles, $\tau_{T}$ is the thermal equilibrium time and it is the time required by the dust cloud to adjust its temperature to that of the fluid, $\tau_{v}$ is the relaxation time of the of dust particle, i.e., the time required by a dust particle to adjust its velocity relative to the fluid, $k^{*}$ is the thermal conductivity. The Rosseland approximation (Brewster, 1972), i.e., the radiative heat flux $q_{r}$ is modeled as

$$
q_{r}=-\frac{4 \sigma^{2}}{3 k_{1}} \frac{\partial T^{4}}{\partial y}
$$

where $\sigma^{*}$ is the Stefan-Boltzman constant and $k_{l}$ is the mean absorption coefficient. Assuming that the differences in the temperature within the flow are such that $T^{4}$ can be expressed as a linear combination of the temperature, one can expand $T^{4}$ in a Taylor's series about $T_{\infty}$ as follows

$$
T^{4}=T_{\infty}^{4}+4 T_{\infty}^{3}\left(T-T_{\infty}\right)+6 T_{\infty}^{2}\left(T-T_{\infty}\right)^{2}+\cdots
$$

By neglecting higher order terms beyond the first degree in $\left(T-T_{\infty}\right)$, we get

$$
T^{4} \cong-3 T_{\infty}^{4}+T_{\infty}^{3} T
$$

Substituting Eq.(3.5) in Eq.(3.3) we obtain

$$
\frac{\partial q_{r}}{\partial y}=-\frac{16 T_{\infty}^{3} \sigma^{*}}{3 k_{1}} \frac{\partial^{2} T}{\partial y^{2}} .
$$

The solution of Eqs (3.1)-(3.2) depends on the nature of the prescribed boundary condition. The two types of heating processes are discussed.

\section{CASE-1: Variable wall temperature (VWT-Case)}

For this heating process, the variable wall temperature is assumed to be a quadratic function of $x$ and it is given by 


$$
\begin{aligned}
& T=T_{w}=T_{\infty}+T_{0}\left[\frac{c x^{2}}{v(1-\alpha t)^{2}}\right] \quad \text { at } \quad y=0, \\
& T \rightarrow T_{\infty}, \quad T_{p} \rightarrow T_{\infty} \quad \text { as } \quad y \rightarrow \infty
\end{aligned}
$$

where $T_{w}$ is the temperature of the wall and $T_{\infty}$ is the constant temperature far away from the sheet.

In order to obtain similarity solution for temperatures $\theta(\eta)$ and $\theta_{p}(\eta)$, define dimensionless variables as follows

$$
\theta(\eta)=\frac{T-T_{\infty}}{T_{w}-T_{\infty}}, \quad \theta_{p}(\eta)=\frac{T_{p}-T_{\infty}}{T_{w}-T_{\infty}}
$$

where $\quad T-T_{\infty}=T_{0}\left[\frac{c x^{2}}{v(1-\alpha t)^{2}}\right] \theta(\eta)$.

Using Eqs (3.6), (3.7) and (3.8) in Eqs (3.1) and (3.2), we get

$$
\begin{aligned}
& (1+N r) \theta^{\prime \prime}(\eta)+\operatorname{Pr}\left[f(\eta) \theta^{\prime}(\eta)-2 f^{\prime}(\eta) \theta(\eta)\right]-\frac{A}{2} \operatorname{Pr}\left[4 \theta(\eta)+\eta \theta^{\prime}(\eta)\right]+ \\
& +a_{1} N \operatorname{Pr}\left[\theta_{p}(\eta)-\theta(\eta)\right]+a_{2} N \operatorname{PrEc}\left[F(\eta)-f^{\prime}(\eta)\right]^{2}=0, \\
& G(\eta) \theta_{p}^{\prime}(\eta)+2 F(\eta) \theta_{p}(\eta)+\frac{A}{2}\left[4 \theta_{p}(\eta)+\eta \theta_{p}^{\prime}(\eta)\right]+b_{1}\left[\theta_{p}(\eta)-\theta(\eta)\right]=0
\end{aligned}
$$

where $\operatorname{Pr}=\frac{\mu c_{p}}{k^{*}}$ is the Prandtl number, $\mathrm{Ec}=\frac{v^{2}}{C_{p} T_{0}}$ is the Eckret number, $N r=\frac{16 T_{\infty}^{4} \sigma^{*}}{3 k_{l} k^{*}}$ is the thermal radiative parameter, $a_{1}=\frac{1}{\rho \tau_{T} c}(1-\alpha t)$ and $b_{1}=\frac{c_{p}}{\tau_{T} c_{m} c}(1-\alpha t)$ are the local fluid-particle interaction parameters for temperature, $a_{2}=\frac{1}{\mu \tau_{v}}(1-\alpha t)$ is the local fluid-particle interaction parameter of velocity.

Using Eqs (3.7) and (3.8), the corresponding boundary conditions for $\theta(\eta)$ and $\theta_{p}(\eta)$ reduce to the following form

$$
\begin{aligned}
& \theta(\eta)=1 \quad \text { at } \quad \eta=0, \\
& \theta(\eta)=0, \quad \theta_{p}(\eta)=0 \quad \text { as } \quad \eta \rightarrow \infty .
\end{aligned}
$$

\section{CASE-2: Variable heat flux (VHF-Case)}

For this heating process, the following variable heat flux boundary condition is employed. 


$$
\begin{aligned}
& \frac{\partial T}{\partial y}=-\frac{q_{w}(x, t)}{k^{*}} \quad \text { at } \quad y=0, \\
& T \rightarrow T_{\infty}, \quad T_{p} \rightarrow T_{\infty} \quad \text { as } \quad y \rightarrow \infty
\end{aligned}
$$

where $\quad q_{w}(x, t)=q_{w_{0}} x^{2}\left(\frac{c}{v}\right)^{3 / 2}(1-\alpha t)^{-5 / 2}$

In order to obtain similarity solution for temperature, define dimensionless temperature variables for the VHF case as in Eq.(3.8) where $T_{w}-T_{\infty}=\frac{q_{w 0}}{k^{*}}\left[\frac{c x^{2}}{v(1-\alpha t)^{2}}\right] \theta(\eta)$.

Using the dimensionless variable (3.8), the temperature Eqs (3.1) and (3.2) take the form

$$
\begin{aligned}
& (1+N r) \theta^{\prime \prime}(\eta)+\operatorname{Pr}\left[f(\eta) \theta^{\prime}(\eta)-2 f^{\prime}(\eta) \theta(\eta)\right]+a_{1} N \operatorname{Pr}\left[\theta_{p}(\eta)-\theta(\eta)\right]+ \\
& +a_{2} N \operatorname{PrEc}\left[F(\eta)-f^{\prime}(\eta)\right]^{2}-\frac{A}{2} \operatorname{Pr}\left[4 \theta(\eta)+\eta \theta^{\prime}(\eta)\right]=0 \\
& G(\eta) \theta_{p}^{\prime}(\eta)+2 F(\eta) \theta_{p}(\eta)+\frac{A}{2}\left[4 \theta_{p}(\eta)+\eta \theta_{p}^{\prime}(\eta)\right]+b_{1}\left[\theta_{p}(\eta)-\theta(\eta)\right]=0
\end{aligned}
$$

The corresponding boundary conditions become

$$
\begin{array}{ll}
\theta^{\prime}(\eta)=-1 \quad \text { at } \quad \eta=0, & \\
\theta(\eta)=0, & \theta_{p}(\eta)=0 \quad \text { as } \quad \eta \rightarrow \infty .
\end{array}
$$

The physical quantities of interest are the skin friction coefficient $c_{f}$ and the local Nusselt number $\mathrm{Nu}_{x}$, which are defined as

$$
c_{f}=\frac{\tau_{w}}{\rho U_{w}^{2}}, \quad \mathrm{Nu}_{x}=\frac{x q_{w}}{k\left(T_{w}-T_{\infty}\right)}
$$

where the surface shear stress $\tau_{w}$ and the surface heat flux $q_{w}$ are given by

$$
\tau_{w}=\mu\left(\frac{\partial u}{\partial y}\right)_{y=0}, \quad q_{w}=k\left(\frac{\partial T}{\partial y}\right)_{y=0}
$$

Using the non-dimensional variables, we obtain

$$
c_{f} \operatorname{Re}_{x}^{1 / 2}=f^{\prime \prime}(0), \quad \mathrm{Nu}_{x} / \operatorname{Re}_{x}^{1 / 2}=-\theta^{\prime}(0)(\mathrm{VWT}), \quad \mathrm{Nu}_{x} / \mathrm{Re}_{x}^{\frac{1}{2}}=1 / \theta(0)(\mathrm{VHF}) .
$$




\section{Numerical solution}

The nonlinear governing partial differential Eqs (2.1) to (2.5) with the boundary condition (2.7) are converted into non-linear ordinary differential equations by using the set of similarity variable (2.8). The obtained highly non-linear ordinary differential equations with the boundary condition (2.13) are solved numerically the with help of symbolic software Maple using the programme given by Aziz (2009). The coupled boundary layer Eqs (2.9) to (2.12) and either Eqs (3.9) and (3.10) or (3.13) and (3.14) were solved by the RKF45 method. The accuracy of this numerical method was validated by a direct comparison with the numerical results reported by Pop et al. (2004) and Singh et al. (2010) with $\left(A=N r=\mathrm{Ec}=\lambda^{*}=0\right)$. Table 1 represents results of this comparison for $f^{\prime \prime}(0)$. It is observed from this table that a very good agreement achieved between the results.

Table 1. Comparison of the values of $f^{\prime \prime}(0)$ for different values of stretching parameter $\lambda$ when $A=\mathrm{Ec}=M=R=N=\lambda^{*}=0$ and $N r=1$.

\begin{tabular}{cccc}
\hline$\lambda$ & Pop et al. (2004) & Singh et al. (2010) & Present result \\
\hline 0.1 & -0.9694 & -0.9696 & -0.9696 \\
0.2 & -0.9181 & -0.9181 & -0.9181 \\
0.5 & -0.6673 & -0.6672 & -0.6672 \\
2.0 & 2.0174 & 2.0173 & 2.0170 \\
3.0 & 4.7290 & 4.7290 & 4.7290 \\
\hline
\end{tabular}

\section{Results and discussion}

The unsteady stagnation point flow towards a permeable vertical surface in the presence of thermal radiation is investigated in this paper. The stretching velocity is assumed to vary linearly with the distance from the stagnation point and the surface temperature was assumed to vary quadratic with the distance from the stagnation point. The boundary layer equations of momentum and heat transfer are solved numerically. The temperature profile $\theta(\eta)$ in VWT case and $\theta^{\prime}(\eta)$ in VHF case are depicted graphically. The numerical solutions are obtained for various values of the parameters such as the unsteadiness parameter $A$, magnetic parameter $M$, suction parameter $R$, fluid particle interaction parameter $\beta$, Prandtl number Pr, mixed convective parameter $\lambda^{*}$, ratio of the free stream velocity parameter to the stretching sheet parameter $\lambda$, Eckert number Ec and thermal radiation parameter $N r$. Figures $1 \mathrm{a}$ and $1 \mathrm{~b}$, represent a horizontal velocity profile of both fluid and dust particles for various values of $A$ when $\operatorname{Pr}=0.71, R=0$, $M=0.1, N=0.2, \beta=0.1$ and $\lambda=0.5$ and 2.0. One can observe from Figs $1 \mathrm{a}$ and $1 \mathrm{~b}$ that the velocity decreases with the increase of the unsteady parameter $A$ for all values of $\lambda$. At $\lambda<1$ an inverted boundary layer is formed due to fact that the velocity of the stretching sheet exceeds the velocity of the in-viscid stream. At $\lambda=1$, there would be no formation of a boundary layer, as the fluid velocity is equal to the surface velocity. It is interesting to note that the thickness of the boundary decreases with increasing values of $A$ and $\lambda$. 

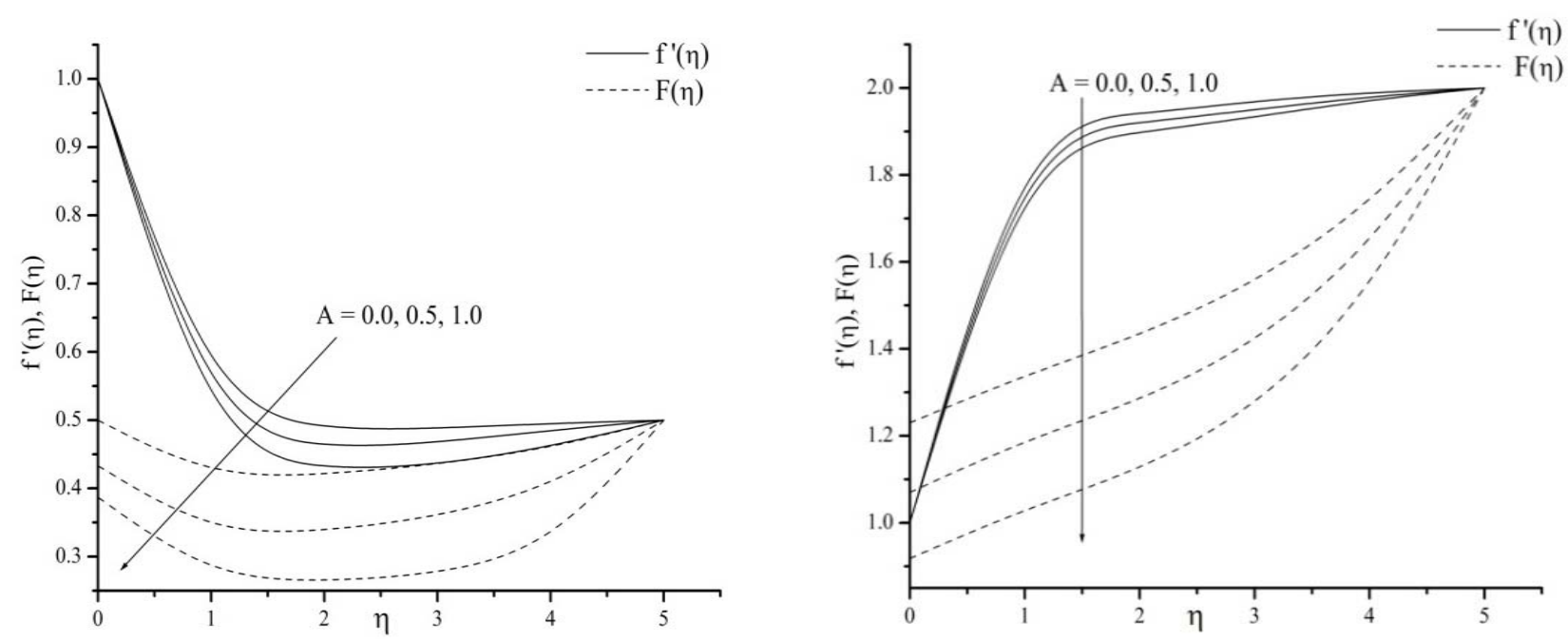

Fig.1a, b. The effect of the unsteady parameter $A$ on the fluid and dust velocity with $\operatorname{Pr}=0.71, R=2, M=0.1$, $N=0.2, N r=1$ and $\beta=1.0, \lambda^{*}=0.1$ when $\lambda=0.5$ and 2 .

The magnetic parameter $M$ represents the impact of a magnetic field on the flow. The presence of a transverse magnetic field evokes Lorentz force, which results in retarding force on the velocity field and therefore as $M$ increases velocity decreases. This is shown in Fig.2a. On the other hand, for a fixed value of $\lambda$ with $\lambda>1$ the velocity at a point increases with an increase in $M$ which is just opposite of $\lambda<1$. This can be explained physically, when $\lambda<1$, the velocity of the stretching sheet exceeds the velocity of the in-viscid stream and an inverted boundary layer is formed near the surface which is shown in Fig. $2 \mathrm{~b}$.
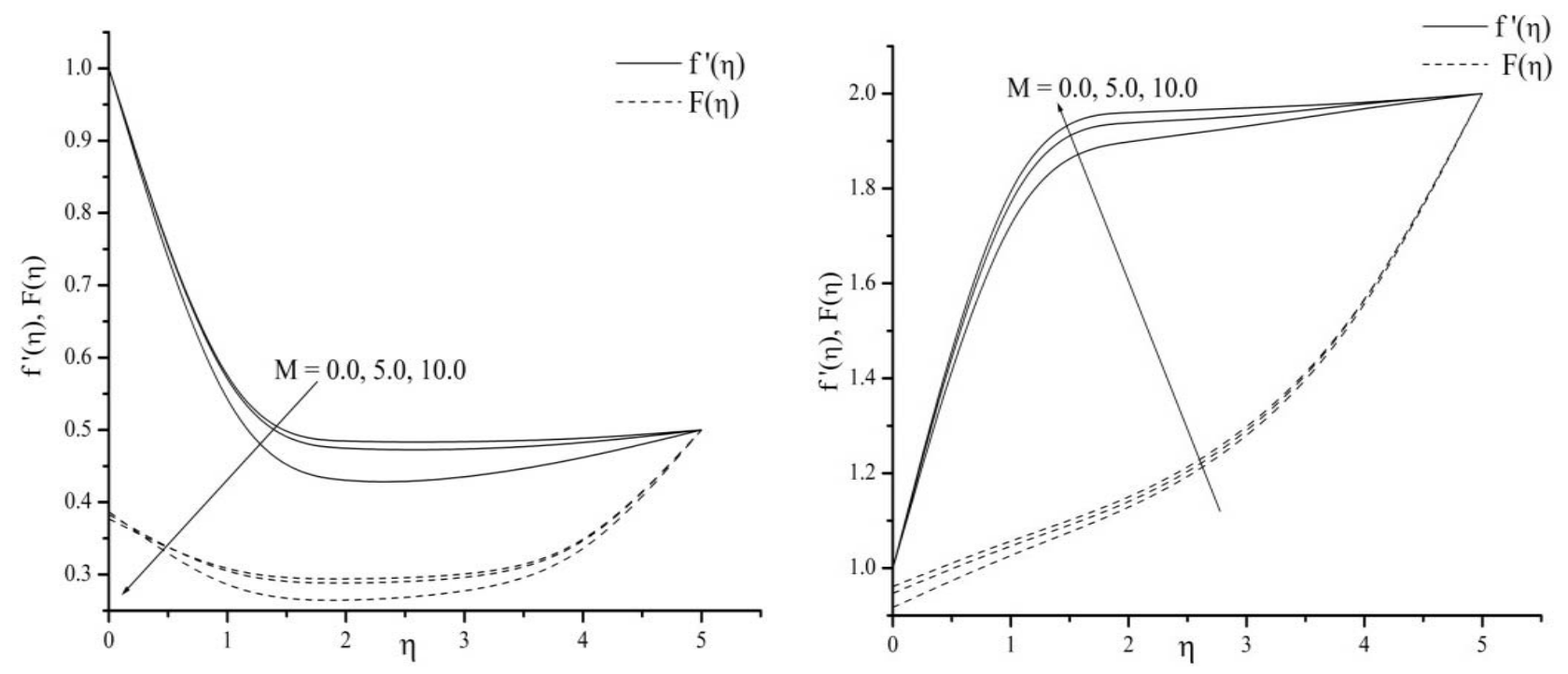

Fig.2a, b. The effect of the Hartman number $\mathrm{M}$ on the fluid and dust velocity with $\operatorname{Pr}=0.71, R=2$, $\mathrm{Ec}=1, N=0.2, \beta=1.0, N r=1$ and $\lambda^{*}=0.1$, when $\lambda=0.5$ and 2 .

It is observed from Tab. 2 that the skin friction decreases as the unsteady parameter increases for $\lambda$ $<1$. Here the negative value of $f^{\prime \prime}(0)$ means that the solid surface exerts a drag force on the fluid. This is due to the development of the velocity boundary layer is caused solely on the stretching plate. For $\lambda>1$, the skin friction increases as the unsteady parameter increases, this is just opposite as in $\lambda<1$. The Nusselt number decreases with an increase in unsteady parameter for both VWT and VHF case. 
Table 2. Skin friction coefficient $f^{\prime \prime}(0)$, wall temperature gradient $\theta^{\prime}(0)$ and temperature function $\theta(0)$ for different values of the unsteady parameter $A$ and stretching parameter $\lambda$.

\begin{tabular}{cccc|ccc}
\hline & \multicolumn{3}{c|}{$\lambda=0.5$} & \multicolumn{3}{c}{$\lambda=2.0$} \\
\hline $\mathbf{A}$ & $f^{\prime \prime}(0)$ & $\theta^{\prime}(0)(V W T)$ & $\theta(0)(V H F)$ & $f^{\prime \prime}(0)$ & $\theta^{\prime}(0)(V W T)$ & $\theta(0)(V H F)$ \\
\hline 0.0 & -1.329816 & -1.303211 & 0.772134 & 3.294316 & -1.612426 & 0.634894 \\
0.3 & -1.432855 & -1.381627 & 0.729675 & 3.273163 & -1.651570 & 0.622599 \\
0.6 & -1.432855 & -1.381627 & 0.693593 & 3.245382 & -1.695132 & 0.612250 \\
1.0 & -1.653356 & -1.552069 & 0.652074 & 3.192132 & 1.745558 & 0.600325 \\
$M$ & & & & & & \\
1.0 & -1.720479 & -1.552638 & 0.651660 & 3.404883 & -1.745558 & 0.600544 \\
3.0 & -1.883692 & -1.551517 & 0.651796 & 3.814236 & -1.750562 & 0.600901 \\
5.0 & -2.041593 & -1.549624 & 0.652323 & 4.165352 & -1.753052 & 0.601132 \\
10.0 & -2.392257 & -1.545092 & 0.653747 & 4.895949 & -1.757667 & 0.601420 \\
& & & & & & \\
1.0 & -1.456613 & -1.559660 & 0.650195 & 3.349023 & -1.747021 & 0.600469 \\
2.0 & -1.071561 & -1.573678 & 0.646739 & 3.661537 & -1.749724 & 0.600803 \\
3.0 & -0.696245 & -1.586351 & 0.643639 & 3.972478 & -1.752135 & 0.601198 \\
4.0 & -0.329229 & -1.597873 & 0.640847 & 4.281977 & -1.754265 & 0.601653 \\
\hline
\end{tabular}

Figures $3 \mathrm{a}$ and $3 \mathrm{~b}$ are a graphical representation for temperature distribution of VWT and VHF case, for different values of the unsteady parameter $A$ versus $\eta$ when $\lambda=0.5$. It is evident that temperature of the fluid and dust particle is found to decrease with an increase of the unsteady parameter $A$. The temperature at a point of surface decreases significantly with the increase of $A$, i.e., the rate of heat transfer increases with increasing the unsteady parameter $A$. Physically, it means that the temperature gradient at the surface increases as $A$ increases, which implies an increase of the heat transfer rate at the surface $-\theta^{\prime}(0)$. We have used throughout our thermal analysis the values of $a_{1}=a_{2}=b_{1}=2$.
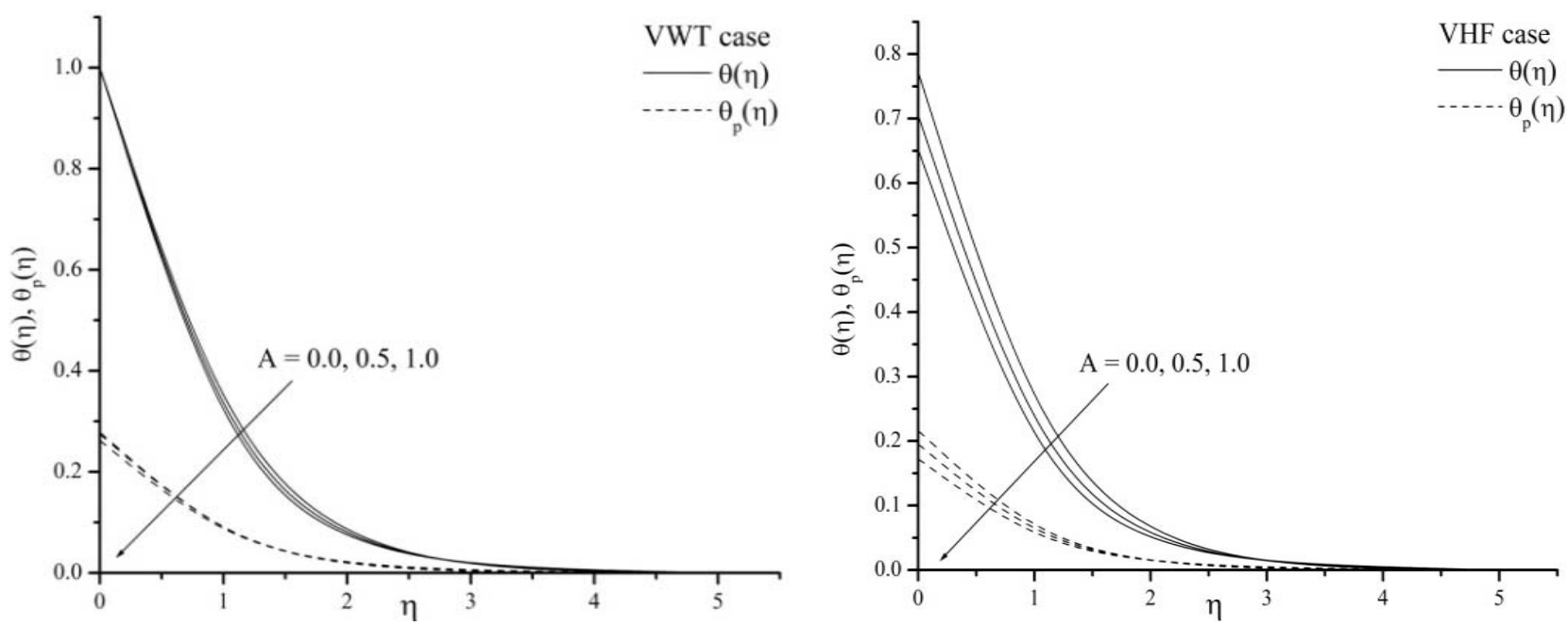

Fig.3a, b. The effect of the unsteady parameter $A$ on temperature distribution with $\operatorname{Pr}=0.71, \mathrm{Ec}=2, R=2$, $M=0.1, N=0.2, \beta=1, \lambda^{*}=0.1, N r=1$ when $\lambda=0.5$. 
Figures $4 \mathrm{a}$ and $4 \mathrm{~b}$ represent the temperature distribution for VWT and VHF case, for different values of the unsteady parameter $A$ versus $\eta$ when $\lambda=2.0$. It shows that the temperature of the fluid and dust particle is found to increase with an increase of the unsteady parameter $A$. The thermal boundary layer thickness decreases with the increase in $A$ and $\lambda$.
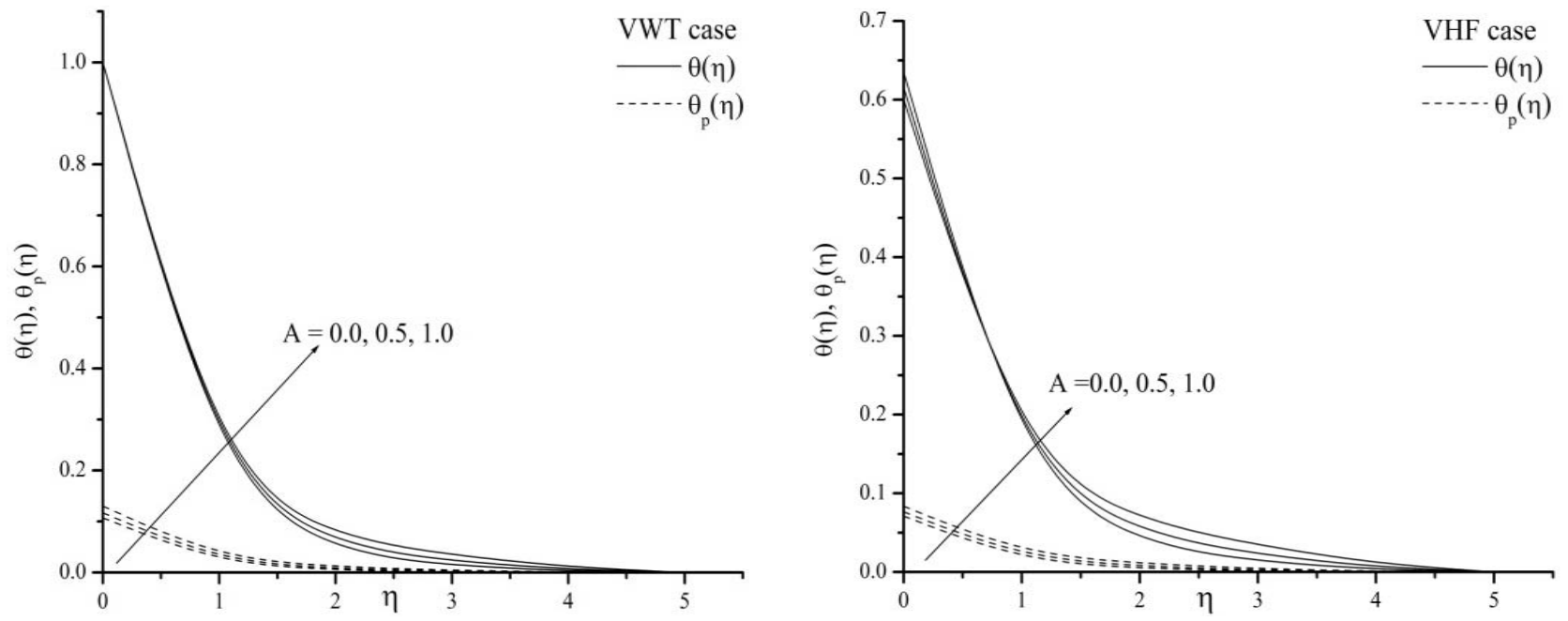

Fig.4a, b. The effect of the unsteady parameter $A$ on temperature distribution with $\operatorname{Pr}=0.71, \mathrm{Ec}=2, R=0.5$, $M=0.1, N=0.2, \beta=2, N r=1, \lambda^{*}=0.1$ when $\lambda=2$.

Figures $5 \mathrm{a}$ and $5 \mathrm{~b}$ depict the horizontal velocity profile of both fluid and dust phase for various values of the buoyancy or mixed convection parameter $\lambda^{*}$ for VWT and VHF case. The velocities of the fluid and dust particle increase with the increasing values of the mixed convective parameter. Physically, $\lambda^{*}>0$ means heating of the fluid or cooling of the boundary surface, $\lambda^{*}<0$ means cooling of the fluid or heating of the boundary surface and $\lambda^{*}=0$ corresponds to the absence of free convection current. This represents the ability of the fluid thermal expansion or the coupling of the temperature field to the velocity field. Increasing $\lambda^{*}$ will amplify the effect of the temperature variation on the velocity field, increase the buoyancy force, and hence will increase the velocity profiles of both the fluid and dust phase and the increase of the boundary layer thickness.
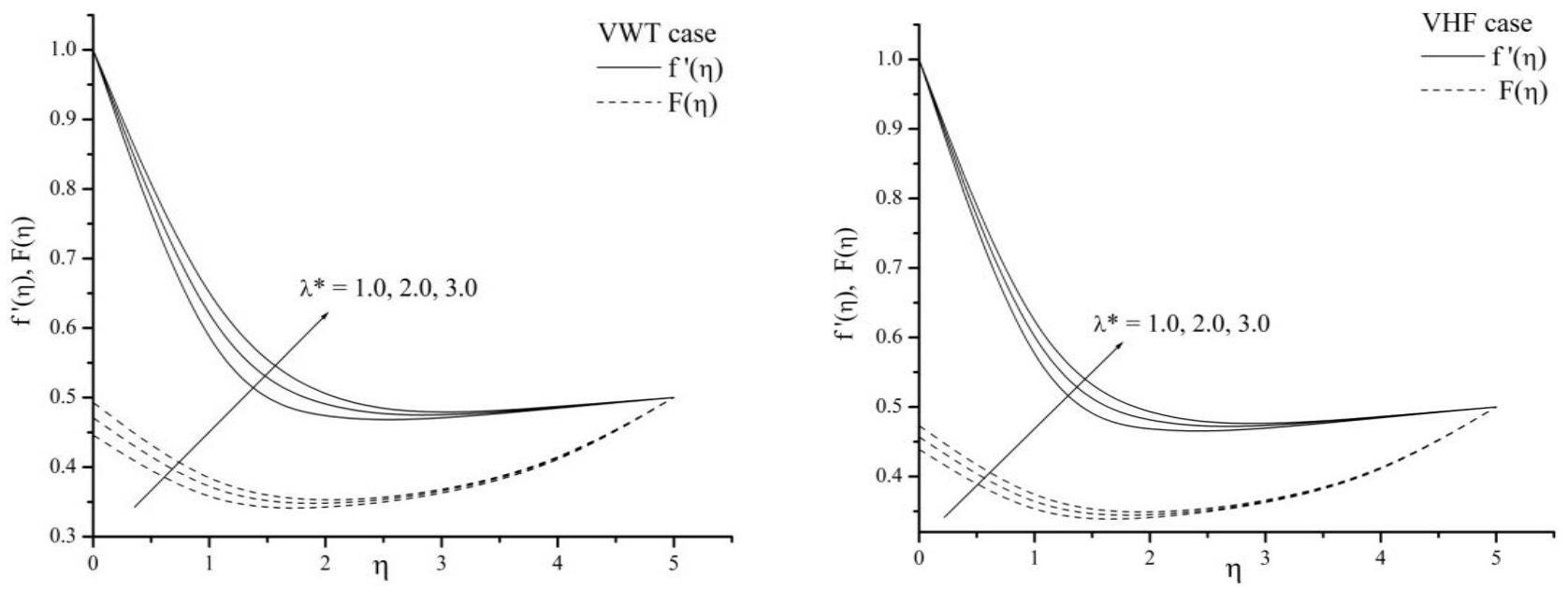

Fig.5a, b. The effect of the convective parameter $\lambda^{*}$ on fluid and dust velocity $A=1.0, \operatorname{Pr}=0.71, \mathrm{Ec}=1, R=2, M=0.1, N=0.2, \beta=1, N r=1$ when $\lambda=0.5$. 
Figures $6 \mathrm{a}$ and $6 \mathrm{~b}$ show that the temperature profiles of the fluid and dust phase decrease with the increasing values of the mixed convective parameter. It is clear that as $\lambda^{*}$ increases the thermal boundary layer thickness decreases. From these figures one can observe that the temperature gradients as well as the thermal boundary layer thickness are decreasing as $\lambda$ increases. The temperature gradient is always negative which means that the heat is transferred from the sheet to the ambient medium. Hence, the heat transferred rate from the sheet to the ambient medium is getting large as $\lambda^{*}$ increases.
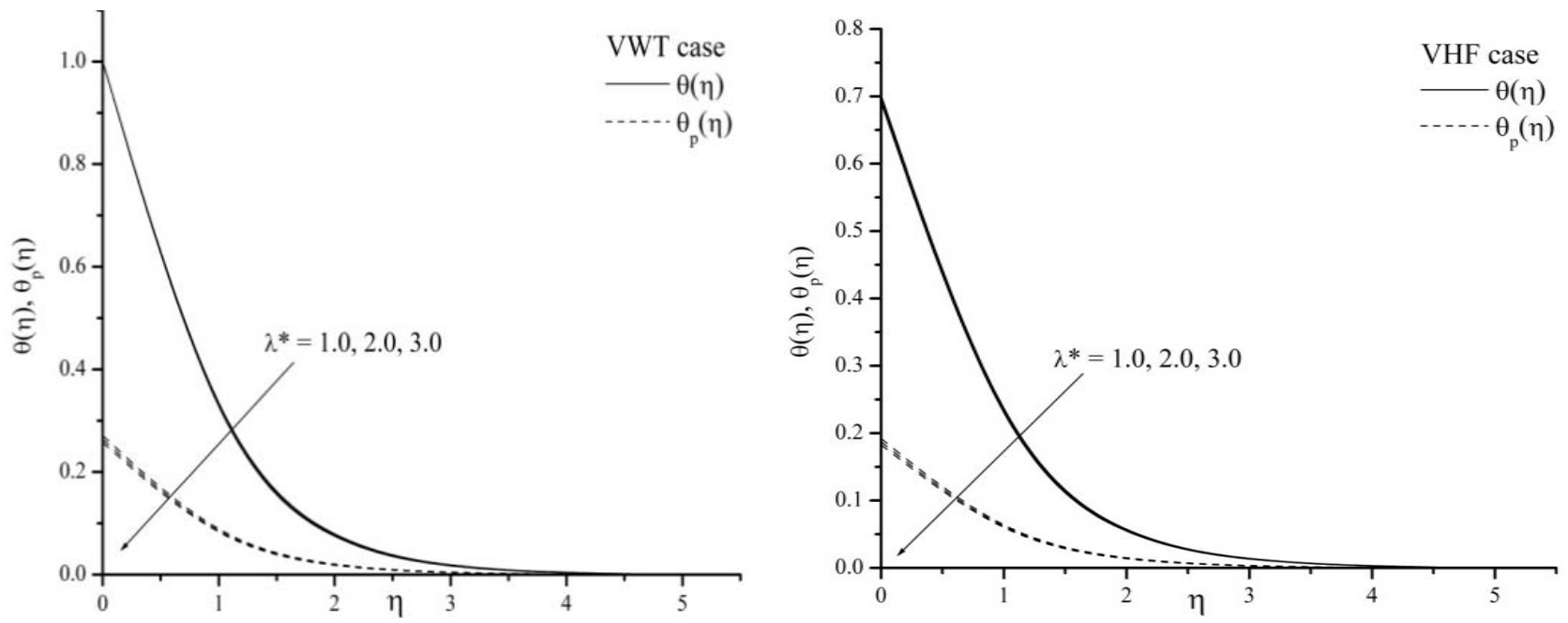

Fig.6a, b. The effect of the convective parameter $\lambda^{*}$ on temperature distribution with $A=1.0, \operatorname{Pr}=0.71, \mathrm{Ec}=1, R=2, M=0.1, N=0.2, N r=1, \beta=1$, when $\lambda=0.5$.

Figures $7 \mathrm{a}$ and $7 \mathrm{~b}$ depict temperature profiles of $\theta(\eta)$ and $\theta_{p}(\eta)$ versus $\eta$, for different values of Pr. We infer from these figures that the temperature of the fluid and dust particles decreases with the increase in $\operatorname{Pr}$, this is because increasing the Prandtl number Pr indicates the increase of the fluid heat capacity or the decrease of the thermal diffusivity, hence causes a diminution of the influence of the thermal expansion to the flow. This implies that the momentum boundary layer is thicker than the thermal boundary layer. The temperature in both VWT and VHF cases asymptotically approaches zero in the free stream region.
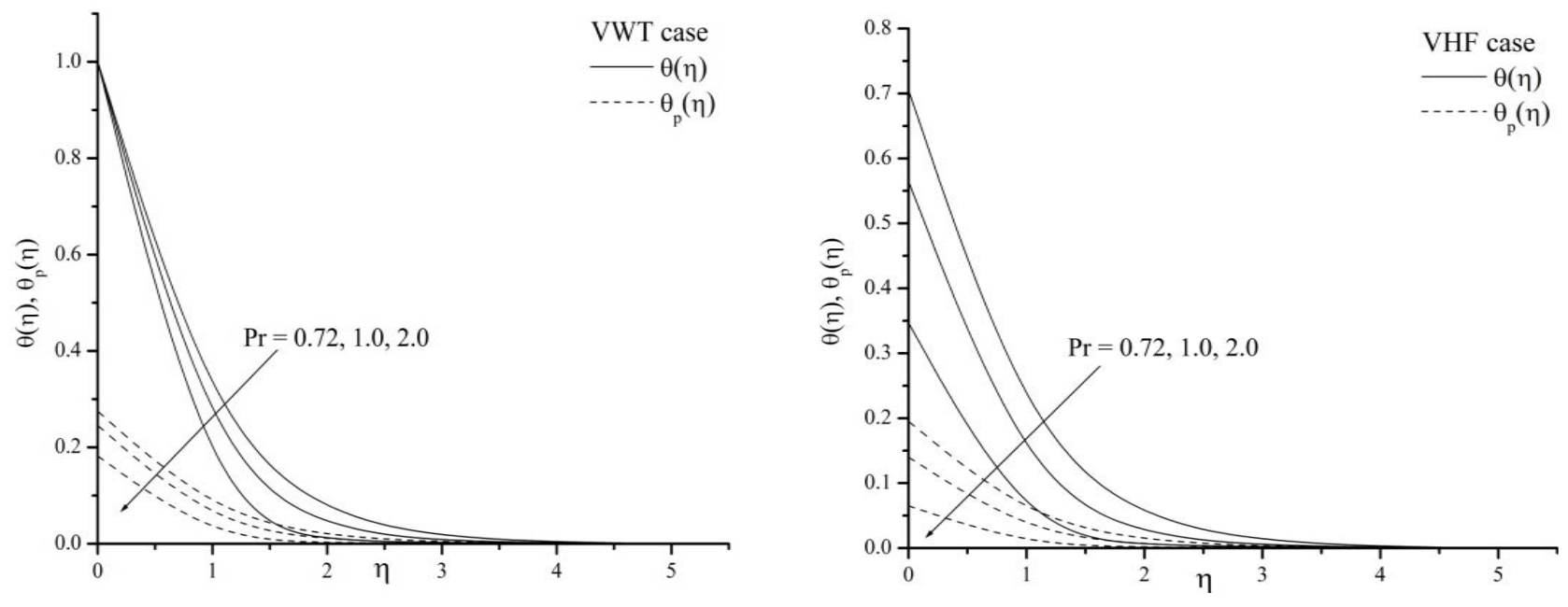

Fig.7a, b. The effect of the Prandtl number $\operatorname{Pr}$ on temperature distribution with $A=1.0, \mathrm{Ec}=1, R=2, M=0.1, N=0.2, \beta=1, N r=1, \lambda^{*}=0.1$ when $\lambda=0.5$. 
Figures $8 \mathrm{a}$ and $8 \mathrm{~b}$ indicate the temperature profile of $\theta(\eta)$ and $\theta_{p}(\eta)$ versus $\eta$, for VWT and VHF cases, respectively. Here an increase in the Eckert number values greatly affects the temperature of the fluid and dust phase. The temperature of the fluid and dust phase increases as the Eckert number increases for both the cases VWT and VHF. This is due to fact that the heat energy is stored in the considered liquid due to frictional heating.
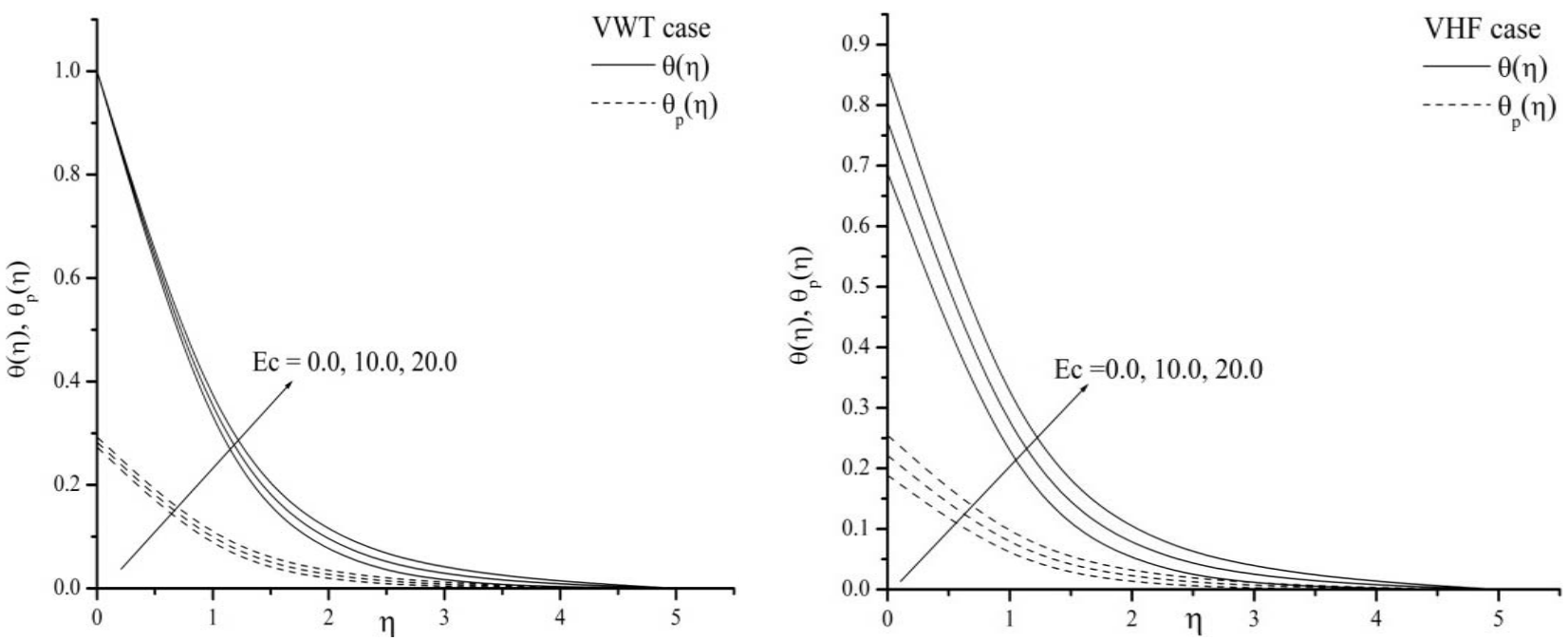

Fig.8a, b. The effect of the Eckert number $\operatorname{Pr}$ on temperature distribution with $A=1.0, \operatorname{Pr}=0.71, R=2, M=0.1, N=0.2, \beta=1, N r=1, \lambda^{*}=0.1$ when $\lambda=0.5$.

Figures $9 \mathrm{a}$ and $9 \mathrm{~b}$ are graphs of temperature profiles of $\theta(\eta)$ and $\theta_{p}(\eta)$ versus $\eta$, for different values of the number density $N$ for VWT and VHF cases, respectively. From the figures, it is observed that the temperature of the fluid and dust phases decreases with the increase of $N$. This is due to increase in number density of dust particles which oppose the flow.
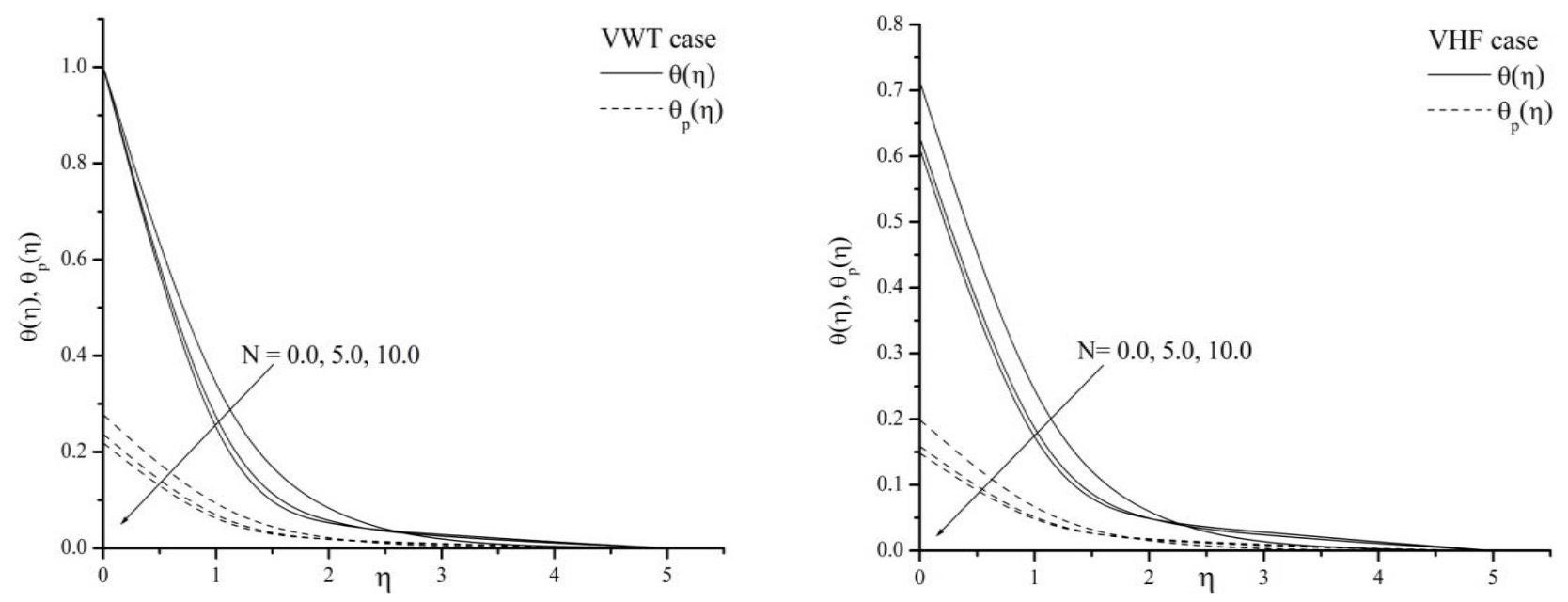

Fig.9a, b. The effect of the number density $N$ on temperature distribution with $A=1.0, \operatorname{Pr}=0.71, R=2, M=0.1, \mathrm{Ec}=1, \beta=1, N r=1, \lambda^{*}=0.1$ when $\lambda=0.5$. 
Figures $10 \mathrm{a}$ and $10 \mathrm{~b}$ represent the temperature profile for various values of thermal the radiation parameter $\mathrm{Nr}$ in case VWT and VHF, respectively. The effect of an increase in the radiation parameter $\mathrm{Nr}$ results in increasing the temperature profiles within the boundary layer as well as an increase in the thermal boundary layer thickness. Thus radiation should be at its minimum in order to facilitate the cooling process.
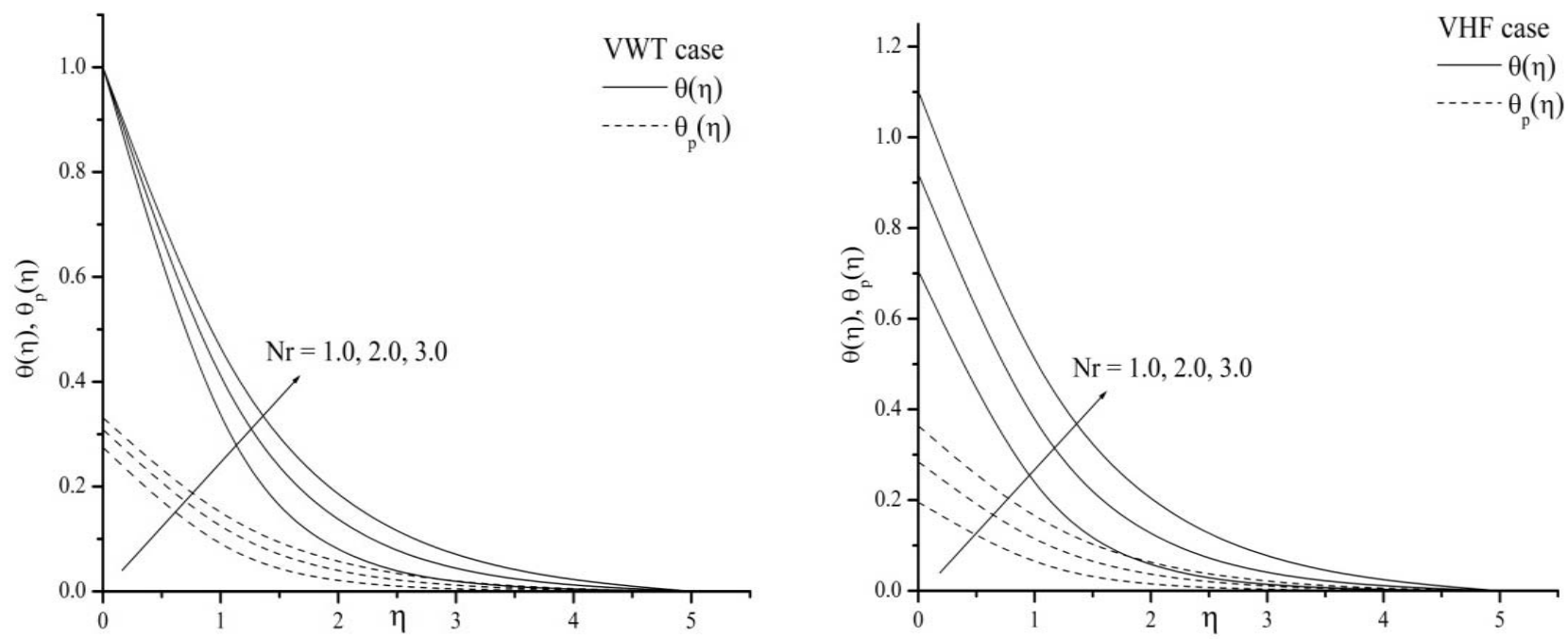

Fig.10a, b. The effect of the thermal radiation parameter $N r$ on temperature distribution with $A=1.0, \operatorname{Pr}=0.71, R=2, \quad M=0.1, \mathrm{Ec}=1, \beta=1, \lambda^{*}=0.1$ when $\lambda=0.5$.

Table 3. Wall temperature gradient $\theta^{\prime}(0)$ and temperature function $\theta(0)$ for different values of the parameters $\beta, A, \operatorname{Pr}, \mathrm{Ec}, N, N_{r}$ and $\lambda$.

\begin{tabular}{ccccccccc}
\hline$\beta$ & $A$ & $\operatorname{Pr}$ & $\mathrm{Ec}$ & $N r$ & $N$ & $\lambda$ & $\theta^{\prime}(\eta)($ VWTcase $)$ & $\theta(\eta)($ VHFcase $)$ \\
\hline 0.1 & 1.0 & 0.72 & 1 & 1 & 0.2 & 2.0 & -1.393051 & 0.731699 \\
0.5 & & & & & & & -1.373634 & 0.736565 \\
1.0 & & & & & & & -1.356271 & 0.743518 \\
0.1 & 1.0 & 0.72 & 1 & 1 & 0.2 & 2.0 & -1.303211 & 0.772134 \\
& 0.5 & & & & & & -1.431652 & 0.705051 \\
& 1.0 & & & & & & -1.552069 & 0.652074 \\
0.1 & 1.0 & 0.72 & 1 & 1 & 0.2 & 2.0 & -1.431652 & 0.705051 \\
& & 1.0 & & & & & -1.800878 & 0.564393 \\
& & 2.0 & & & & & -3.001597 & 0.346698 \\
0.1 & 1.0 & 0.72 & 1 & 1 & 0.2 & 2.0 & -1.456747 & 0.688186 \\
& & & 0.5 & & & & -1.450478 & 0.692397 \\
& & & 2.0 & & & & -1.431652 & 0.705051 \\
0.1 & 1.0 & 0.72 & 1 & 1 & 0.2 & 2.0 & -1.431652 & 0.705051 \\
& & & & 2 & & & -1.090351 & 0.919212 \\
& & & & 3 & & & -0.905431 & 1.101434 \\
0.1 & 1.0 & 0.72 & 1 & 1 & 0.2 & 2.0 & -1.468613 & 0.694449 \\
& & & & & 1.5 & & -1.579101 & 0.668556 \\
0.1 & 1.0 & 0.72 & 1 & 1 & 0.2 & 1.0 & -1.441376 & 0.645270 \\
& & & & & & 2.0 & -1.459011 & 0.696248 \\
& & & & & & 3.0 & -1.474623 & 0.691316 \\
\hline
\end{tabular}




\section{Conclusions}

The problem of mixed convection flow near a two-dimensional stagnation point on a vertical, continuously stretching sheet immersed in an incompressible viscous dusty fluid in the presence of thermal radiation has been investigated. The highly non-linear momentum Eqs (2.1) to (2.5) and heat transfer boundary layer Eqs (3.1) to (3.2) are converted into coupled ordinary differential equations by using similarity transformations. The resultant coupled ordinary differential Eqs (2.9) to (2.12) and (3.9) to (3.10) for VWT case and (3.13) to (3.14) for VHF case have been solved numerically by the method employed by Aziz (2009) i.e., the RKF45 method. The results are analyzed for the situation when a stretching boundary is prescribed by non-isothermal variable wall temperature (VWT) which varies quadratically with the flow directional coordinate $x$. The effect of various physical parameters such as the unsteady parameter $A$, Prandtl number Pr, Eckret number Ec, Hartmann number M, ratio of free stream velocity parameter to stretching sheet parameter $\lambda$, mixed convective parameter $\lambda^{*}$ and thermal radiation parameter $N r$ on various momentum and heat transfer characteristics are obtained. Some of the interesting observations are listed as follows;

- Increasing the stretching parameter increases the velocity components but decreases the velocity boundary layer thickness.

- The fluid and dust phase velocities decrease due to an increase in the magnetic parameter for $\lambda<1$, while a reverse effect is observed, when $\lambda>1$.

- The effect of the unsteady parameter decreases the temperature profile of the fluid and dust phases for both the cases of VWT and VHF when $\lambda<1$.

- The effect of the unsteady parameter increases the temperature profile of the fluid and dust phases for both the cases of VWT and VHF $\lambda>1$.

- At $\lambda=1.0$, there is no formation of a boundary layer.

- The effect of the thermal radiation parameter increases the temperature profile of the fluid and dust phases for both the cases of VWT and VHF.

- Always, the rate of heat transfer $\theta^{\prime}(0)$ is negative and $\theta(0)$ is positive.

- $\theta^{\prime}(0)$ and $\theta(0)$ increase with the increase of the radiation parameter, fluid interaction parameter and Eckert number.

- The increase in the Prandtl number decreases the thermal boundary layer thickness.

- If $A \rightarrow 0, \beta \rightarrow 0, \mathrm{Nr} \rightarrow 1, \lambda^{*} \rightarrow 0, M \rightarrow 0$ and $N \rightarrow 0$ then our results coincide with the results of Pop et al. (2004) and Singh et al. (2010) for various values of $\lambda$.

\section{Acknowledgement}

We wish to express our thanks to the University Grant Commission, New Delhi, for financial support to pursue this work under a Major Research Project (F.No.36- 147/2008/(SR)/dated:26-03-2009).

\section{Nomenclature}

$$
\begin{gathered}
A=\frac{\alpha}{c} \quad \text { - unsteadiness parameter } \\
a_{1}=\frac{1}{\rho \tau_{T} c}(1-\alpha t) \quad-\text { local fluid-particle interaction parameters for temperature } \\
a_{2}=\frac{1}{\mu \tau_{v}}(1-\alpha t) \quad-\text { local fluid-particle interaction parameter of velocity }
\end{gathered}
$$




$$
\begin{aligned}
& B_{0} \quad \text { - induced magnetic field } \\
& b_{I}=\frac{c_{p}}{\tau_{T} c_{m} c}(1-\alpha t)-\text { local fluid-particle interaction parameters for temperature } \\
& c_{m} \quad \text { - specific heat of dust particles } \\
& c_{p} \text { - specific heat of fluid } \\
& E \text { - density ratio } \\
& \mathrm{Ec}=\frac{v^{2}}{C_{p} T_{0}}-\text { Eckert number } \\
& \mathrm{Gr}_{x}=\frac{g \beta^{*}\left(T_{w}-T_{\infty}\right) x^{2}}{v^{2}}-\text { local Grashof number } \\
& K \text { - Stoke's constant } \\
& k^{*}-\text { thermal conductivity } \\
& l=\frac{m N}{\rho_{p}} \quad-\text { mass concentration } \\
& M=\frac{\sigma B_{0}^{2}}{\rho b}-\text { magnetic field parameter } \\
& N \text { - number of dust particles } \\
& N r=\frac{16 T_{\infty}^{4} \sigma^{*}}{3 k_{1} k^{*}}-\text { thermal radiative parameter } \\
& \mathrm{Nu}_{x}-\text { Nusselt number } \\
& \operatorname{Pr}=\frac{\mu c_{p}}{k^{*}}-\text { Prandtl number } \\
& q_{w} \quad \text { - surface heat flux } \\
& R=\frac{v_{0}}{\sqrt{v c}} \text { - suction parameter } \\
& \operatorname{Re}_{x}=\frac{u_{w} x}{v}-\text { local Reynolds number } \\
& T \text { - temperature of the fluid phase } \\
& T_{p} \text { - temperature of the dust particle phase } \\
& T_{w} \quad \text { - temperature of the wall } \\
& T_{\infty} \quad \text { - constant temperature far away from the sheet } \\
& U(x, t)=\frac{b x}{1-\alpha t}-\text { free stream velocity } \\
& U_{w}=\frac{c x}{1-\alpha t}-\text { velocity of the sheet } \\
& (u, v) \text { - velocity components of the fluid phase along the } x \text { - and } y \text {-axis } \\
& \left(u_{p}, v_{p}\right) \text { - velocity components of the particle phase along the } x \text { - and } y \text {-axis } \\
& V_{w}(x, t)=-\frac{v_{0}}{\sqrt{(1-\alpha t)}} \quad-\text { suction velocity } \\
& \alpha \text { - positive constant which measures the unsteadiness } \\
& \beta=\frac{1}{\tau b}(1-a t) \text { - fluid-particle interaction parameter } \\
& \beta^{*}-\text { volumetric coefficient of thermal expansion } \\
& \lambda=\frac{b}{c} \quad \text { ratio of free stream velocity parameter to stretching velocity parameter }
\end{aligned}
$$




$$
\begin{aligned}
\lambda^{*}=\frac{\mathrm{Gr}_{x}}{\operatorname{Re}_{x}^{2}} & - \text { mixed convective parameter } \\
\mu & - \text { co-efficient of viscosity of the fluid } \\
\rho & - \text { density of the fluid } \\
\rho_{p} & - \text { density of particle phase } \\
\rho_{r}=\frac{\rho_{p}}{\rho} & - \text { relative density } \\
\tau_{T} & - \text { thermal equilibrium time } \\
\tau_{v} & - \text { relaxation time of the dust particle } \\
\tau_{w} & - \text { shear stress }
\end{aligned}
$$

\section{References}

Abdul Aziz (2009): A similarity solution for laminar thermal boundary layer over a flat plate with a convective surface boundary condition. - Com. Non. Sci. Numer. Simulat., vol.14, pp.1064-1068.

Brewster M.Q. (1972): Thermal Radiative Transfer Properties. - John Wiley and Sons.

Chen C.H. (1998): Laminar mixed convection adjacent to vertical, continuously stretching sheets. - Heat Mass Transfer, vol.33, pp.471-476.

Chiam T.C. (1996): Heat transfer with variable conductivity in a stagnation-point flow towards a stretching sheet. - Int. Comm. Heat Mass Transfer, vol.23, pp.239-248.

Devi C.D.S., Takhar H.S. and Nath G. (1991): Unsteady mixed convection flow in stagnation region adjacent to a vertical surface. - Heat Mass Transfer, vol.26, pp.71-79.

Gireesha B.J., Manjunatha S. and Bagewadi C.S. (2011): Unsteady hydromagnetic boundary layer flow and heat transfer of dusty fluid over a stretching sheet. - Int. J. Afrika Metametika, vol.22 (In press).

Gireesha B.J., Ramesh G.K., Subhas Abel M. and Bagewadi C.S. (2011): Boundary layer flow and heat transfer of a dusty fluid flow over a stretching sheet with non- uniform heat source /sink. - Int. J. Multiphase Flow, vol.37, No.8, pp.977-982.

Gireesha B.J., Ramesh G.K., Lokesh H.J. and Bagewadi C.S. (2011): Boundary layer flow and heat transfer of a dusty fluid over a stretching vertical surface. - Applied Mathematics, vol.2, pp.475-481.

Hiemenz K. (1911): Dei Grenzschicht an einem in den gleichformigen Flussigkeitsstrom einge- tauchten geradenKreiszylinder. - Dingl. Polytech. Journal, vol.32, 321-410.

Ishak A. (2010): Thermal boundary layer flow over a stretching sheet in a micropolr fluid with radiation effect. Meccanica, vol.45, pp.367-373.

Ishak A., Nazar R. and Pop I. (2006): Magnetohydrodynamic stagnation-point flow towards a stretching vertical sheet. - Magnetohydrodynamics, vol.42, pp.17-30.

Ishak A., Nazar R. and Pop I. (2006): Mixed convection boundary layers in the stagnation-point flow toward a stretching vertical sheet. - Meccanica, vol.41, pp.509-518.

Lok Y.Y., Amin N., Campean D. and Pop I. (2005): Steady mixed convection flow of a micropolar fluid near the stagnation point on a vertical surface. - Int. J. Numerical Methods Heat Fluid Flow, vol.15, pp.654-670.

Lok Y.Y., Amin N. and Pop I. (2006): Unsteady mixed convection flow of a micropolar fluid near the stagnation point on a vertical surface. - Int. J. Thermal Sci., vol.45, pp.1149-1157.

Mahapatra T.R. and Gupta A.S. (2001): Magnetohydrodynamic stagnation-point flow towards a stretching sheet. - Acta Mech., vol.152, 191-196.

Nazar R., Amin N., Filip D. and Pop I. (2004): Unsteady boundary layer flow in the region of the stagnation point on a stretching sheet. - Int. J. Engng. Sci., vol.42, pp.1241-1253. 
Pop I., Pop S.R. and Grosan T. (2004): Radiation effect on flow near the stagnation point. - Technische Mechanik, vol.2, pp.100-106.

Ramachandran N., Chen T.S. and Armaly B.F. (1988): Mixed convection in stagnation flows adjacent to avertical surfaces. - ASME J. Heat Transfer, vol.7, No.110, 373-377.

Schlichting H. (1968): Boundary Layer Theory. - New York: McGraw-Hill.

Shercliff J.A. (1965): A Text Book of Magneto-Hydromagnetics. - London: Pergamon Press.

Singh P., Jangid A., Tomer N.S. and Sinha D. (2010): Effects of thermal radiation and magnetic field on unsteady stretching permeable sheet in presence of free stream velocity. - Int. J. of Information and Mathematical Sciences, vol.03, pp.160-166.

Takhar H.S., Chamkha A.J. and Nath G. (2005): Unsteady mixed convection on the stagnation-point flow adjacent to a vertical plate with a magnetic field. - Heat Mass Transfer, vol.41, pp.387-398.

Vajravelu K. and Nayfeh J. (1992): Hydromagnetic flow of a dusty fluid over a stretching sheet. - Int. J. Nonlinear Mechanics, vol.27, No.6, pp.937-945.

Received: December 27, 2014

Revised: October 6,2015 